\title{
Research on the growth of dye film in vacuum in situ
}

Grytsenko, K., Doroshenko, T., Kolomzarov, Yu., Prokopets, V., Fedoriak, O., et al.

K. Grytsenko, T. Doroshenko, Yu. Kolomzarov, V. Prokopets, O. Fedoriak, R. Zelinski, O. Lytvyn, D. Prescher, B. Grimm, V. Ksianzou, S. Schrader, O. Tolmachev, Yu. Slominskii, V. Kurdiukov, G. Smirnova, "Research on the growth of dye film in vacuum in situ," Proc. SPIE 6999, Organic Optoelectronics and Photonics III, $69991 Z$ (25 April 2008); doi: $10.1117 / 12.780707$

SPIE. Event: SPIE Photonics Europe, 2008, Strasbourg, France 


\title{
Research on the growth of dye film in vacuum in situ
}

\author{
K.Grytsenko ${ }^{1}$, T.Doroshenko ${ }^{1}$, Yu.Kolomzarov ${ }^{1}$, V.Prokopets ${ }^{1}$, O.Fedoriak ${ }^{1}$, R.Zelinski ${ }^{1}$, \\ O. Lytvyn ${ }^{1}$, D. Prescher ${ }^{2}$, B.Grimm ${ }^{2}$, V.Ksianzou ${ }^{2}$, S.Schrader ${ }^{2}$, O.Tolmachev ${ }^{3}$, Yu.Slominskii ${ }^{3}$, \\ V.Kurdiukov ${ }^{3}$, G.Smirnova ${ }^{3}$. \\ ${ }^{1}$ Institute of Semiconductor Physics, Kyiv, Ukraine, \\ ${ }^{2}$ Institute of Photonics, Laser \& Plasma Technology, University of Applied Sciences \\ Wildau, Germany, \\ ${ }^{3}$ Institute of Organic Chemistry, 5 Murmanska str., Kyiv, Ukraine
}

\begin{abstract}
Organic film deposition in vacuum is fast developing scientific and industrial domain. We developed installation for deposition of organic films equipped with optical spectrometer for measurements in situ. We are developing new dyes aimed for application in waveguide sensor, nonlinear optics and studying film organisation during deposition. Fluorinated azo-dyes and azomethine dyes were synthesized at University of Applied Sciences Wildau and at the Institute of Organic Chemistry, Kyiv. Compounds were evaporated at a pressure of $10{ }^{3} \mathrm{~Pa}$ using resistive heated crucible. Glass and glass covered with polytetrafluoroethylene (PTFE) film are used as substrates. The films were studied with Polytec and StellarNet spectrometers and an atomic force microscope. Optical spectra of the dye films revealed, that some compounds were decomposed during evaporation. Several kinds of dyes were evaporated and deposited without decomposition. Some deposited films formed H-aggregates and other types of aggregates. AFM images of dye films showed that their morphology depends on the chemical structure of the compounds and on the nature of the substrate on which the film was grown.
\end{abstract}

\section{KEYWORDS}

Dye, solid, film, in situ, optical spectra, vacuum deposition.

\section{INTRODUCTION}

Organic low molecular mass compounds (dyes) are using in different novel industrial branches: organic light emitting diodes and organic field effect transistors (OLED and OFET), sensor, integrated optic devices etc. A lot of scientific researches were making to understand evaporability and film formation ${ }^{1-4}$. A dye is a large molecule (in comparison with inorganic matter) with complex shape and complex distribution of physical forces on its surface. This peculiarity leads to possibility of formation of different molecular packing for the one dye solid film, which dependent on the both dye chemical structure and deposition conditions. Different aggregations have low energy of phase transformation, so influence of deposition conditions plays important role for formation of dye film with wanted properties. Apparatuses and methods used for studies of inorganic film growth in situ can be used for dye film studies in very limited cases due to absence of conductivity for many dyes and due to energy action is destroying dye molecules. So only optical methods should be used. Optical spectra of dye film measured in situ supplying not only film thickness, but also some information concerned organization and properties of solid ${ }^{5-9}$. Asymmetric azo-dyes were chosen for investigation due to they are represent interest for nonlinear (NLO) devices. Polymethine dyes can be used for NLO devices, for sensors and solar energy conversion.

The aim of this research is to study organization of dye films during their growth by optical spectroscopy in situ .

*Corresponding author: Tel. +380 445255937 /Fax +380 44 5255530;

e-mail: d.grytsenko@gmail.com; d_gryts@isp.kiev.ua 


\section{EXPERIMENTAL}

Different kinds of fluorinated azo- and azomethine dyes were synthesized at the University of Applied Sciences Wildau. according method $4 \mathrm{in}^{10,11}$. The azomethin dye DP-21 could be obtained by dehydratation of an equivalent mixture of aromatic amine and aldehyde in boiling ethanol.

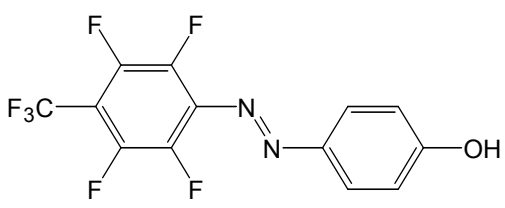

DP-01

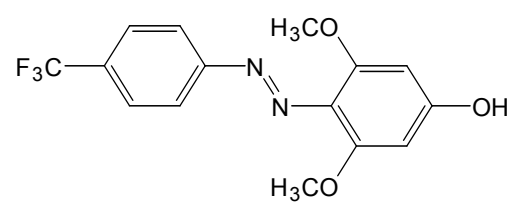

DP-04

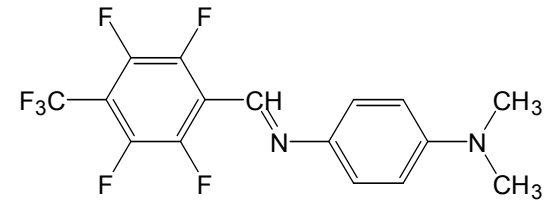

DP-21

Fig.1. Formulae of the azo-dyes used.

Methine dyes were synthesized in Institute of Organic Chemistry, Kyiv. Two types of intraionic (merocyanine) dyes were investigated. The $1^{\text {st }}$ one was the bases of asymmetric monomethine cyanine derivatives of benzo[c,d]indole $(2400$, $2401,2403,2404$ and 2406). The $2^{\text {nd }}$ type was the bases of di-tert-butyl-substituted p-hydroxystyryl dyes $(7496,7482$, 7488, 7483, 7476, 7477 and 7497). Compounds of the $1^{\text {st }}$ type were synthesized like it was described earlier ${ }^{12}$. Compounds of the $2^{\text {nd }}$ type were synthesized under the reaction used in $^{13}$ for the preparation of merocyanine derivative of pyridine 7476 . We would like to mention that it was impossible to obtain films for dyes similar to bases of oxystyryls 7476 and 7483 but without tert-butyl substituents by precipitation from gas phase. The reasonable explanation for this fact could be a lower thermal stability of compounds.

2400<smiles>CN1C=CC(=CC2=Nc3cccc4cccc2c34)c2ccccc21</smiles>

2401<smiles>CN1C(=CC2=Nc3cccc4cccc2c34)Sc2ccccc21</smiles>

7482<smiles>C1=CN(c2ccccc2)c2ccccc2C1=CC1=Nc2cccc3cccc1c23</smiles><smiles>C=C1C(=O)C(C(C)(C)C)=C(C(C)(C)C)C=C1C=CN1C(=CCCCCCCC)N(CC)c2ccccc21</smiles><smiles>CN1C(c2ccccc2)=CC(=CC=c2cc(-c3ccccc3)c(C(C)(C)C)cc2=CC(C)(C)C)C=C1C(C)(C)C</smiles><smiles>CN1C(c2cccs2)=CC(=CC=C2C=C(C(C)(C)C)C(=O)C(C(C)(C)C)=C2)C=C1c1cccs1</smiles>

Fig.2. Formulae of the methine dyes used. 
Vacuum deposition installations UVN-74 and VUP-5M (made in USSR) were used. Compounds were evaporated at a pressure of $10-{ }^{3} \mathrm{~Pa}$ using resistive heated quartz crucible. Glass and glass covered with PTFE film are used as substrates. The films were studied with Polytec and StellarNet spectrometers and quartz thickness monitor Sigma in situ and an atomic force microscope (AFM) NanoScope IIIa Dimension $3000^{\mathrm{TM}}$ ex-situ.

\section{RESULTS AND DISCUSSION}

Several azo-dyes were decomposed during heating in vacuum. Films of azo-dyes were grown in steady mode with no structural transformations. Their absorption bands are positioned around $400 \mathrm{~nm}$ and represent widened band of dye in solution. Film aggregation strongly dependent on dye chemical structure, in several cases no continuous film was formed. DP-01, DP-04 and some other dyes formed films. DP-1 dye film has densely packed structure, DP-04 has elongated packs of needles, DP-21 forms discontinuous mesh.

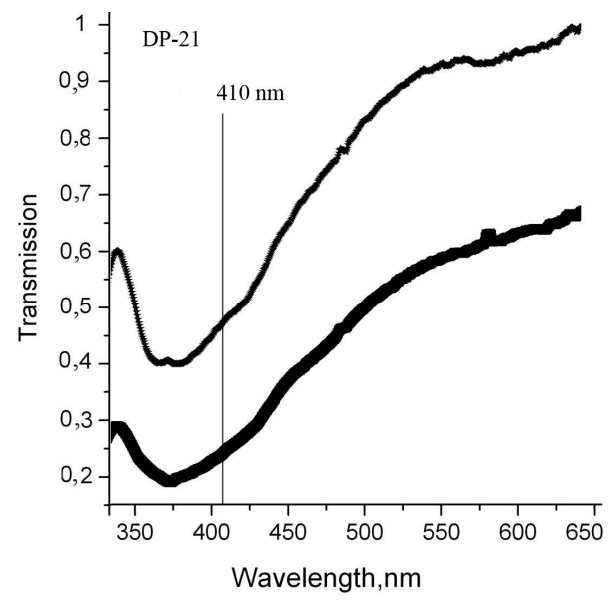

Fig. 3. Spectra of DP-21 dye recorded in situ.

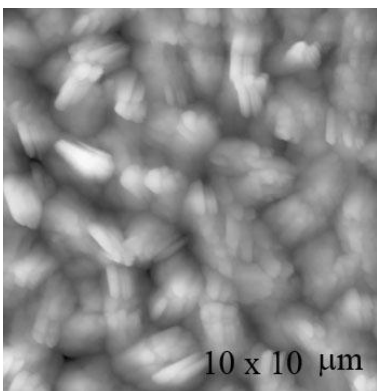

DP- 01

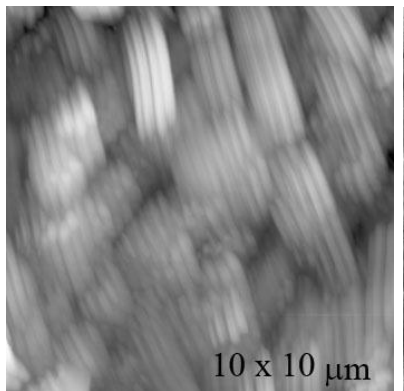

DP -04

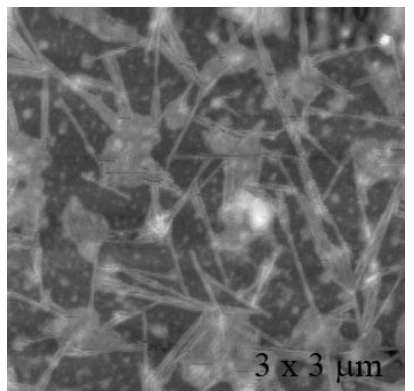

DP- 21

Fig.4. AFM images of fluorine-containing azobenzene and azomethine chromophores, grown on glass. Film thicknesses $250 \mathrm{~nm}$.

Optical transmission spectra of most interesting methine dyes obtained during film growth are shown in Fig.5. Their AFM images are presented in Fig.6. 2400 dye formed no film, but aggregates up to several micrometers in size. 2401 formed film with aggregates about $40 \mathrm{~nm}$. First two dyes show steady growth mode, while 2403 dye shows structure transformation with film thickness growth. AFM images of 2403 dye films show, that structure with short wavelength band has smaller structural units, while structure with long wavelength band has larger elongated aggregates. No significant differences in optical spectra of these three dye films, grown on glass and PTFE. . 2400 and 2401 dye film formation begins from aggregation, while 2403 dye at first is in monomeric state, aggregates are forming with film thickness growth. Dye 7497 showed stronger short wavelength band on glass, while on PTFE longer wavelength band is more intensive. Film growing on glass shows structural transformation with film thickness elevation. H-aggregates are forming on glass substrate with film growth, while on PTFE no such aggregates formation. 7482 and 7496 dyes showed no significant 
difference in spectra on glass and PTFE during growth. Both dyes show monomeric band splitting due to intermolecular interaction in solid.
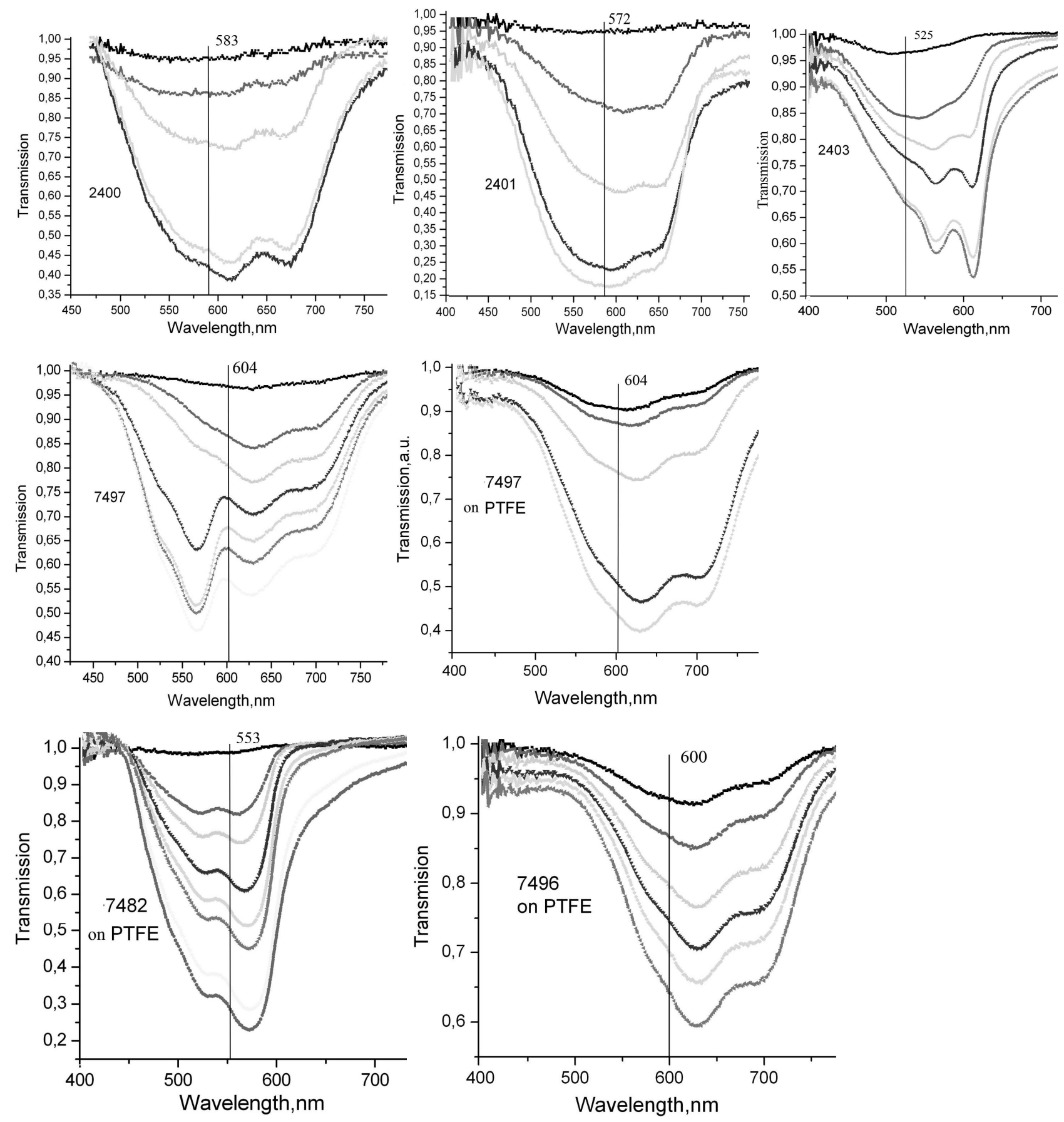

Fig.5. Spectra of methine dye films recorded in situ. 


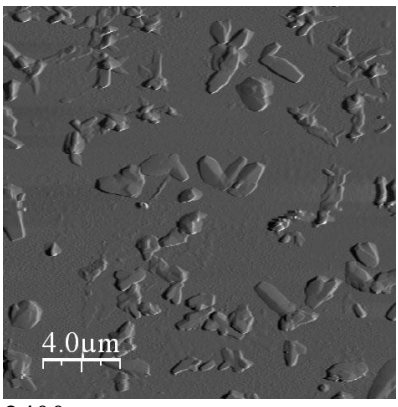

2400

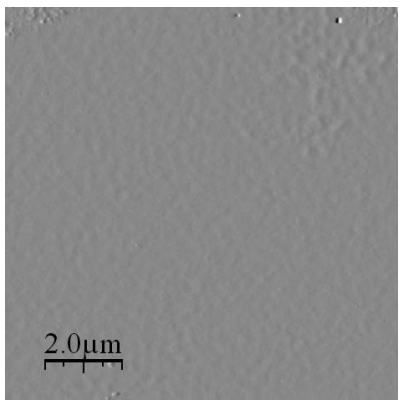

7497 on glass

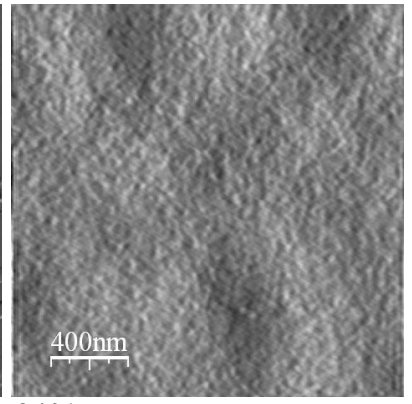

2401

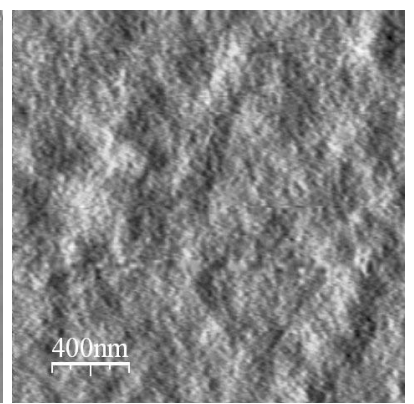

7497 on PTFE

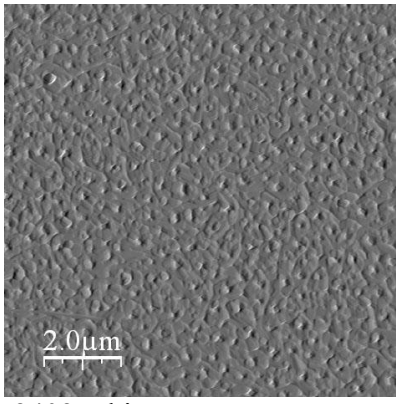

2403 thin

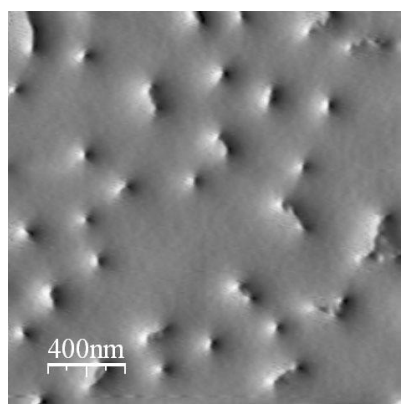

7482 on PTFE

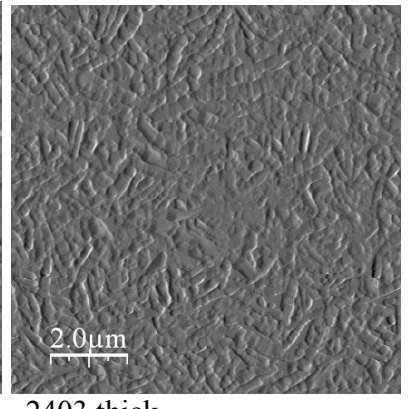

2403 thick

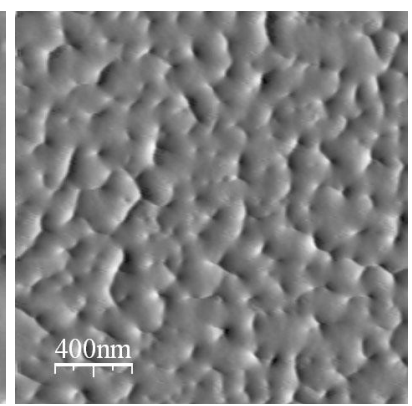

7496 on PTFE

Fig.6. AFM images of the surface of methine dye films.

\section{CONCLUSIONS}

Optical properties of the dye film can be pre-constructed at stage of dye synthesis, but deposition conditions also play important role, affecting optical properties through aggregation and structure of the film. Optical spectroscopy in situ is the powerful method, which allows control of film properties. Structure and optical properties of the film can be controlled by changing of dye side groups. The formation of the discontinuous solid of some compounds should be taken into account, if it to be used in multilayered system.

\section{ACKNOWLEDGMENTS}

Financial support by STCU Grant 3480 (EU), NATO CL Grant and gift of Polytec spectrometers by DAAD are greatly acknowledged.

\section{REFERENCES}

[1] K.P.Gritsenko, D.A.Grinko, A.D.Leonets et al., "Vacuum deposition of organic dyes and their optical properties", Proc. Conf. "Vacuum Coatings-87", Riga, 2, 127 (1987).

[2] H.Bottcher, T.Fritz, J.Wright, "Fabrication of evaporated dye films and application" J.Mater.Chem. 3, 1187-1196 (1993).

[3] K.P.Gritsenko, Yu.L.Slominsky, K.Fedotov, "Vacuum-deposited dye films and their optical properties", Proc. SPIE, 3359,479 (1997).

[4] S.R. Forrest, "Ultrathin Organic Films Grown by Organic Molecular Beam Deposition and Related Techniques," Chemical Reviews, 97,3, 1793-1896 (1997).

[5] K.P.Gritsenko, D.O.Grinko, O.P.Dimitriev, S.Schrader, A.Thierry, J.C.Wittmann, "Oriented Growth of Squaraine Dyes on Uniaxially Aligned Poly(tetrafluoroethylene) Surfaces", Optical Memory and Neural Networks, N3, 135-143 (2004). 
[6] K.P.Grytsenko, S.Schrader, "Nanoclusters in polymer matrices prepared by co-deposition from a gas phase", Advances in Colloid and Interface Science, 116, 263-276 (2005).

[7] Forker, R., Dienel, T., Fritz, T. \& Müllen, K. "Optical evidence for substrate-induced growth of ultrathin hexa-perihexabenzocoronene films on highly oriented pyrolytic graphite" Phys. Rev. B 74, 165410 (2006).

[8] L.D. Sun, "Growth of sexithiophene (6T) films studied by RDS", Abstr. Book, Winter School on Organic Electronics, Plannearlm, 21, (2007).

[9] K. Maschek, Y. Hu, L.D. Sun, M. Hohage and P. Zeppenfeld, "Characterization of organic thin films by optical means", Abstr. Book, Winter School on Organic Electronics, Plannearlm, 19 (2007).

[10] T. Thiele, D. Prescher, R. Ruhmann und D. Wolf, "Synthesis of 4-(1H,1H-perfluoroalkoxy)-4'-(6-methacryloyloxyhexyloxy)-azobenzenes and their liquid crystalline intermediates", J. Fluorine Chem. 85, 155-161 (1997).

[11] S. Schrader, R. Wortmann, D. Prescher, K. Lukaszuk, A. Otto, "Solvatochromy and electrooptical study of new fluorine-containing chromophores", Proc. SPIE, 3474, 14-22 (1998).

[12] G.E. Ficken, J.D. Kendall, "The reactivity of the alkylthio-group in nitrogen ring compounds. Part II. Cyanine bases from 3,3-dimethyl-2-methylthio-3H-indole”, J.Chem. Soc., 6, 1537-154 (1960).

[13] I. Gruda, F. Bolduc, "Spectral properties and basicity of stilbazolium betaines containing bulky substituents on the quinoid ring", J. Org. Chem. 49, 3300-3305 (1984). 